\title{
CRISES, ALTERNATIVAS E AS PERSPECTIVAS DO MARXISMO ECOLÓGICO: entrevista com o Professor Elmar Altvater
}

Joana Emmerick Seabra Julian Araujo Brito Tadzio Peters Coelho ${ }^{1}$

\section{APRESENTAÇÃO}

Para este volume, entrevistamos o professor Elmar Altvater, que está visitando o Brasil para um ciclo de conferências na UERJ, e nos concedeu uma interessante entrevista acerca de sua obra, a conjuntura mundial aberta pela crise econômica em 2008, a situação na América Latina e na Europa, bem como as possíveis alternativas sistêmicas que se abrem à crise capitalista.

Elmar Altvater é politólogo e catedrático de Economia Política da Universidade Livre de Berlin, instituição da qual é professor emérito. Além disso, é membro do conselho científico de Attac/Alemanha (Association for the Taxation of Financial Transactions and for Citizens' Action). Altvater publicou vários artigos e livros sobre globalização e crítica ao capitalismo, tendo como temas de trabalho a teoria do desenvolvimento, crise da dívida, regulação dos mercados, e os efeitos do modo de produção capitalista sobre o meio ambiente. É considerado um dos principais pensadores marxistas da atualidade, com destaque para sua abordagem das relações entre o marxismo e ecologia. Seu penúltimo trabalho, " $O$ fim do Capitalismo como o conhecemos" foi publicado no Brasil em 2010 (Editora Civilização Brasileira).

Intratextos: Professor, para começar, você poderia nos contar um pouco sobre sua trajetória intelectual e militante?

Elmar Altvater: Bom, eu fui, já como aluno na escola, antes de ir à universidade, politicamente ativo. Nessa época, eu era do Partido Social-Democrata (SPD). Foi uma outra época, é muito difícil comparar essa época com os dias atuais, sobretudo na Alemanha. A Alemanha foi um país dividido, a parte oriental era comunista e a outra parte, ocidental, pertencente ao chamado "Ocidente Livre". A nossa geração na Alemanha Ocidental foi caracterizada por um anticomunismo dominante e militante. Eu, particularmente, não era anticomunista, mas também não era comunista, e por isso tive muitas dificuldades na escola. Essas experiências foram muito importantes para minha trajetória posterior. Depois, como estudante universitário, fui membro da

${ }^{1}$ Estudantes do Programa de Pós-Graduação em Ciências Sociais (PPCIS) da UERJ.

INTRATEXTOS, Rio de Janeiro, 4(1): 312-326, 2012.

Página 312 
União Socialista dos Estudantes Alemães (Sozialistischer Deutscher Studentenbund), muito conhecida porque promoveu a revolta estudantil dos anos 1960 na Alemanha. Nesta época comecei os estudos na Universidade de Munique. Foi muito difícil nas universidades alemãs neste momento, porque não havia muita gente que estivesse interessada em mudar as coisas, que pareciam estar muito bem. Nos anos 1950, 1960, vivíamos sob o chamado milagre econômico, altas taxas de crescimento, rápida mudança do padrão de vida em sentido positivo, uma repetição do modo de consumo ocidental norte-americano, e por isso, foi muito difícil para o movimento crítico socialista nas universidades. Poucas pessoas se interessavam por política. Isso só foi mudar após os bombardeios dos Estados Unidos no Vietnã, em 1964. Depois da crise do Golfo de Tonkin, quando os norte-americanos começaram os bombardeios, surgiu um novo movimento contra a intervenção dos EUA no Vietnã. Isso foi em 1964. E, depois, pouco a pouco o movimento estudantil foi crescendo. Isso foi um dos acontecimentos, mas tiveram outras experiências marcantes.

Destaco também o surgimento de uma nova geração antinazista e suas brigas com os familiares que aderiram ao nazismo. Foi um importante conflito de gerações neste momento. Hoje é diferente, porque não existem mais os responsáveis pelos crimes do nazismo. Naquela época, eu mesmo tive familiares que foram oportunisticamente responsáveis ou corresponsáveis pelo nazismo. Por isso houve um grande debate intergeracional entre a juventude e seus familiares remanescentes do nazismo; os jovens não aceitavam aquelas posições políticas. Esse foi um segundo ponto.

O terceiro ponto foi que, em 1967, o milagre econômico alemão surpreendentemente acabou para muita gente, interrompido por uma crise econômica, que produziu um milhão de desempregados. Um milhão hoje parece não ser muito coisa, mas naquela época foi uma coisa muito séria, uma pequena catástrofe. Neste momento alguns sociólogos escreviam que uma taxa de desemprego maior do que 5\%, um milhão de pessoas sem emprego formal, significaria uma potencial revolução. Poderia ser o estopim de uma revolução social e política. Foi uma ilusão, nós sabemos, mas muitos acreditaram exatamente nisto. Mas a crise foi um choque para muita gente. Muito se escreveu sobre isso, nos Estados Unidos, provavelmente aqui no Brasil, na Alemanha e em todos os outros países europeus. Muitos estudiosos da economia política ou da economia convencional, da sociologia, pensaram que o ciclo de crises havia acabado, que não haveria mais crises, ou seja, acreditavam na capacidade do intervencionismo estatal para 
estabilizar o sistema capitalista. Vocês podem consultar, sobre este aspecto, a obra de Jürgem Habermas, por exemplo, quando escrevia exatamente isso: o Estado intervencionista keynesiano é capaz de resolver todas as crises do capitalismo, e por isso não existem mais aquelas contradições econômicas do capitalismo que foram objeto de estudo dos velhos marxistas. Essa foi uma terceira experiência, a crise econômica.

E, depois, uma quarta experiência, muito importante para a Alemanha, foi a formação da chamada grande coalizão, entre a social democracia e a democracia cristã. Isso significou que na Alemanha não havia mais uma oposição parlamentar, além do pequeno e politicamente fraco partido liberal. O Parlamento seria apenas de suporte ao governo e, por isso, os estudantes dessa época constituíram a chamada "oposição extra-parlamentar". Isso foi uma experiência única na Europa, porque em outros países europeus ocidentais ainda havia um importante partido comunista, como na Itália e na França. Por outro lado, em países como a Espanha e Portugal, e na Grécia desde 1967, tivemos ditaduras. Foi uma época com ditaduras fascistas, com novas ditaduras militares, como na Grécia, com uma grande coalizão que não conhecia uma oposição no Parlamento, esta alternância entre partidos e oposições de governo. Então esses foram os pontos mais importantes, têm outros também que são menos importantes.

Então, isso tudo foi muito importante para a dinâmica do movimento, as lutas de classe que tiveram nessa época. No fim dos anos 1960 na Itália teve o outono quente, e na França o maio de 1968; os novos movimentos socialistas radicais - revolucionários - tiveram um determinado impacto também na Alemanha. Nós viajávamos, por exemplo, para a Itália, para a França, para estabelecer novos contatos políticos, e isso foi muito importante para depois desenvolvermos também o pensamento. Foi o caminho para aprender as teorias de Gramsci, que foram muito importantes para compreender o que aconteceu na Alemanha. Sobretudo para entender a experiência do nazismo. Na Alemanha, você não pode imaginar, tivemos desde 1933 uma ditadura brutal, criminosa, que inclusive levou a uma guerra mundial, com 50 milhões de vítimas. E, depois, a divisão do país. Muitos opositores do lado ocidental migraram para o oriente. Alguns voltaram, porque não foi tão agradável na República Democrática Alemã. No geral, isso foi importante para o desenvolvimento de uma esquerda na Alemanha Ocidental, assim como os contatos estabelecidos com outros países europeus que ainda tinham um partido comunista, um partido socialista. Meus primeiros estudos de Marx começaram com a ajuda de alguns marxistas de outros países, e que contribuíram muito para a esquerda alemã, como Ernest 
Mandel, que também é conhecido no Brasil. Foi muito importante, porque ele é alemão de origem, fala perfeitamente alemão, mas viveu na Bélgica e foi conhecido em todo o mundo. Mandel foi importante ao traduzir muitas obras do pensamento crítico marxista, de origem francesa, por exemplo, para os discursos políticos na Alemanha.

\section{Intratextos: E nesse tempo você militou em alguma organização política, sindicato?}

Elmar Altvater: Não, não foi possível. Fui membro do Partido Social Democrata, como falei. Mas só até 1961. Em 1961, o SPD decidiu que não era possível ser um membro do partido e, ao mesmo tempo, membro da União Socialista dos Estudantes Alemães. Porque não era possível? Porque a União Socialista foi contra o rearmamento. O rearmamento deu início a um grande debate nessa época na Alemanha, inclusive o armamento nuclear, atômico, na OTAN (Organização do Tratado do Atlântico Norte). E o SPD decidiu, num congresso do partido, no famoso Congresso de Bad Godesberg, que se adotasse a linha da democracia cristã e isso foi algo duro para União Socialista. Por isso, cada um teve que decidir entre ficar na União Socialista ou ficar no SPD. Eu fiquei na União Socialista e decidi deixar o partido. E depois eu nunca fui de um partido porque não existia um partido da esquerda. O partido comunista da Alemanha Ocidental existiu até 1958, mas, em 1958, ele foi proibido e considerado ilegal ser membro do partido comunista. E então, além disso, não foi muito atrativo ser um membro do partido comunista, porque na Alemanha Oriental as coisas não foram boas para o socialismo e para a atratividade da ideia socialista. Fui membro de um partido só ao fim deste ciclo, no fim dos anos 1970, início dos anos 1980, quando fui um dos primeiros membros do Partido Verde. Mas deixei este partido em 2001, quando se decidiu apoiar a invasão dos EUA ao Afeganistão e participar da guerra na Iugoslávia.

\section{Intratextos: Qual foi sua formação acadêmica, seus objetos de estudo?}

Elmar Altvater: Eu estudei em Munique, economia e sociologia. Depois realizei um segundo estudo, uma pós-graduação. Era um estudo sobre os países Orientais, sobre os "socialismos realmente existentes". Estudei a língua russa e as instituições soviéticas, as constituições dos países da Europa Oriental, e os sistemas de planejamento econômico. Isso foi um segundo estudo, 
mas não foi muito útil, porque o "socialismo realmente existente" - após um curto período de tempo - não era mais realmente existente, mudou. Já nos tempos em que ainda existia, como nome, não era o socialismo como nós imaginamos uma sociedade socialista. E depois eu escrevi uma tese de doutorado, também em Munique. Fui pesquisador no Instituto de Pesquisa Social, em Nuremberg, e depois professor em Ciências Políticas e Economia Política, em Berlim.

Intratextos: Professor, em sua trajetória, você se posicionou de forma clara na crítica ao capitalismo, tendo informado importantes debates não apenas na academia, mas com o conjunto dos movimentos sociais. Como você vê esta relação entre academia e militância, ou quais as possibilidades de atuação para o pesquisador/intelectual engajado?

Elmar Altvater: A questão que se coloca é a da responsabilidade científica, o que significa que os estudos têm que ser uma coisa muito séria. Por isso é necessário, sendo militante ou não, observar as regras da ciência, do método científico. Mas as regras da ciência crítica devem servir, digamos, a alguma coisa. Se pudéssemos resumir em poucas palavras: à emancipação do homem. Esclarecimento é outra palavra muito importante. Isso é o que os cientistas têm que organizar num processo no qual eles participam em conjunto, porque nunca é só um ou uma, mas são muitos. Segundo ponto, com relação aos movimentos sociais, os sindicatos. No Brasil, por exemplo, os sindicatos, o MST (Movimento dos trabalhadores Rurais Sem Terra), os novos movimentos sociais têm perguntas, colocam problemas que devem ser resolvidos. E, para a resolução, sempre os cientistas podem ser úteis. Podem ser, não necessariamente! E nunca sozinhos, sempre em diálogo com os movimentos. Não é que os cientistas tenham as soluções e os movimentos tenham que segui-las. Terceiro ponto, os cientistas têm que ser parte dos movimentos, eles não podem estar fora, mas sim devem estar dentro dos movimentos. Isso não é fácil. Quando você trabalha na universidade, tem as atividades internas à vida universitária, e por outro lado tem que lidar com os desafios que os movimentos sociais colocam à sociedade de modo mais amplo. Então temos que produzir e colaborar na universidade, que é o nosso trabalho, por um lado, e também temos que colaborar com os movimentos. E, às vezes, isso é demais para uma pessoa só. Então, penso que esses três pontos, essas três dimensões, são importantes: a responsabilidade científica, com vistas ao progresso científico, é fundamental; a busca por soluções para os problemas trazidos pelos movimentos sociais, considerados sempre sob o 
aspecto da emancipação social; e, sobretudo, a participação dos cientistas nos movimentos sociais, desde os sindicatos até os movimentos ambientais, por exemplo.

\section{Intratextos: Quais são as idéias centrais do seu livro "O fim do capitalismo como o conhecemos"? Apesar da crise iniciada em 2008, que aspectos você destacaria que constitui o capitalismo contemporâneo?}

Elmar Altvater: Esse livro foi escrito antes da crise. A publicação em alemão foi em 2005, e desta forma, a crise financeira não foi o tema mais importante nesse livro, embora ele contenha um capítulo sobre a crise financeira. Neste livro busquei analisar os limites do desenvolvimento capitalista, que são as suas próprias contradições internas; os choques externos; os limites dos recursos naturais, em particular da energia fóssil, e não só isso. O capitalismo, desde o fim do século XVIII, com a chamada Revolução Industrial, tem um regime energético que é intrínseco ao seu próprio funcionamento. Foi estabelecido um regime energético fechado, limitado. Entretanto, antes deste fechamento, seu sistema foi aberto à radiação solar. Isso é infinito, mas não era possível fomentar os processos de transformação produtiva, de transporte e de comunicação, tão rápidos como hoje em dia. Isso só foi possível com as energias fósseis, e por isso o regime energético do capitalismo foi fechado, baseado em recursos limitados. Isso é uma novidade na historia da humanidade, e é claro que isso não pode durar para sempre. Por causa desses limites, não é possível que o sistema capitalista continue infinitamente seguindo a sua trajetória dos últimos dois séculos. É absolutamente impossível. Justamente por isso, temos “o fim do capitalismo como nós o conhecemos". Existia um capitalismo antes das energias fósseis, antes da Revolução Industrial, um capitalismo de matriz energética não-fóssil. Não tivemos navios a vapor, navios a vela, que foram dependentes da radiação solar, do vento, da energia eólica? Existia um capitalismo não tão acelerado como o capitalismo depois da Revolução Industrial e, por isso, poderíamos dizer, talvez, que teremos um capitalismo pós-fóssil, enquanto matriz energética. A questão então é a seguinte: o capitalismo pós-fóssil talvez seja possível, mas talvez a população, os homens, as pessoas, prefiram um outro tipo de sociedade, um outro modo de produção para organizar a reprodução social, não dependente das energias fósseis, mas das energias renováveis. Isso nós não sabemos. Nós conhecemos o que aconteceu no passado, mas não conhecemos o que vai acontecer no futuro. O futuro é um resultado da nossa atuação, e muita 
gente participa desta realização. É um projeto muito autoritário dizer que a sociedade tem que se organizar desse ou daquele modo. Por isso eu digo: o capitalismo chega ao fim, como o conhecemos até aqui, ou seja, baseando sua reprodução em uma matriz energética fóssil. Mas, no futuro, temos de criar um novo capitalismo, ou pós-capitalismo, e isso é a tarefa das novas gerações, dos movimentos sociais e políticos.

\section{Intratextos: Com relação à globalização, depois da euforia dos anos 90, como você vê este ideário hoje?}

Elmar Altvater: Em 1996, 1997, e anteriormente a crise mexicana, em 1994, e depois a crise no Brasil, na Argentina... ou seja, tivemos crise durante toda a década. Por isso considero que, de fato, este ideal não tenha alcançado nenhuma euforia nesta década. E começaram algumas guerras. A guerra na Iugoslávia, por exemplo, mas não só. Na África, houve muitas guerras nessa época. Mas, por outro lado, a globalização foi um pouco idealizada nessa época, porque a gente dizia, como o economista americano Edward Luttwak: a globalização não conhece mais inimigos, porque não existe uma lógica binária da distinção entre amigos e não-amigos, existe uma lógica múltipla, só têm competidores. E os competidores nunca começam uma guerra entre sí, não tem interesse numa guerra porque custa caro demais. Então, essa idealização não existe mais. Hoje em dia, se fala menos em globalização, e muito mais em geopolítica, novos conflitos geopolíticos, e um novo imperialismo, que David Harvey, por exemplo, analisa; também menciono em meu último livro. Contudo, a globalização foi a época da geoeconomia. Depois da globalização, no novo imperialismo, temos uma época da geopolítica novamente. Por isso, há conflitos duros, em muitas áreas de atuação. Poderíamos observar os conflitos sobre a moeda global; conflitos entre o dólar e o euro; ou conflitos sobre as novas moedas, talvez o Yuan; a China é um ator muito importante neste jogo global. Essa é uma das dimensões dos conflitos. Outra, são ligados aos recursos naturais. O fim da energia fóssil, o fim dos metais raros, que são tão importantes para a transformação da energia solar em energia útil, dá inicio à conflitos que têm de ser regulados. Ninguém sabe se essa regulação vai garantir a paz indefinidamente, ou se vai estourar, também é possível... não podemos prever isso. Por isso, a boa esperança na globalização acabou. 


\section{Intratextos: Atualmente a União Européia parece passar por um amplo processo de deterioração, em que as imposições da TROIKA $^{2}$ desconsideram a soberania política e nacional dos países mais fragilizados. Por outro lado temos a ascensão da contestação nas ruas. Como você analisa a crise européia? E o papel da Alemanha?}

Elmar Altvater: Este é um grande tema. Um tema muito triste. Porque a integração européia é um dos projetos mais importantes da época do pós II Guerra. Na verdade, a União Européia ganhou o prêmio Nobel [da paz] no início de outubro. É verdade que na Europa não houve, nas ultimas seis décadas, guerra. Embora não seja completamente justificada essa posição, pois tivemos as guerras da Iugoslávia, na região do Cáucaso, e a participação de poderes europeus em guerras na África, no Oriente Médio, na Ásia, etc. Então, não é completamente justo este prêmio. Apesar disso, é um fato muito importante, pois nunca havia existido, nos últimos séculos na Europa, uma época de paz de seis décadas. Isso é importante.

Tivemos uma integração, por um lado negativa, através dos processos de liberalização dos mercados e desregulamentação política, ou seja, realizou-se um projeto neoliberal. A dimensão negativa é que a União Européia é um projeto neoliberal. Mas, por trás disso, existem alguns processos com aspectos positivos: o aumento do contato entre os estudantes, por exemplo, o que não é fácil na Europa. Mudar de uma Universidade da Alemanha, digamos, para a França, ou da Bélgica para a Suíça, a distância geográfica é pequena, muito menor que as distâncias geográficas aqui no Brasil, mas as distâncias culturais são enormes. São outros idiomas, costumes, os hábitos são diferentes, as tradições políticas e culturas são diferentes. A integração positiva consiste exatamente numa intensificação do intercâmbio entre os países europeus, ativamente, subsidiados pela União Européia. Para estudantes, mas para professores também, para pessoas ativas na cultura, para os jovens de todas as profissões, tal intercâmbio é muito importante.

Outro ponto importante foi a criação da moeda européia, o Euro. Na época do tratado de Maastricht ${ }^{3}$, no início dos anos 90, eu fui contra este processo de introdução da moeda única, porque como economista, eu sabia que uma moeda comum precisaria de uma política monetária, fiscal e econômica em comum. Muitos governos são contra essa comunidade política. Eles são a

\footnotetext{
${ }^{2}$ Equipe de negociação da dívida dos países europeus composta pela Comissão Europeia, Banco Central Europeu e Fundo Monetário Internacional.

${ }^{3}$ Tratado assinado em Maastricht, Holanda, em 7 de fevereiro de 1993.
} 
favor da comunidade monetária, mas não a favor da comunidade política. Isso é uma contradição que faz todo o sistema estourar. Isso é o que vem acontecendo nos últimos dois anos.

É importante compreender que a crise européia não é apenas européia. A crise do Euro, da dívida, não começou na Europa, mas nos EUA, como crise financeira do setor das hipotecas subprime, setor com títulos de menor valor. A liberalização dos mercados financeiros, nos anos 70, foi uma das causas. Os mercados criaram inovações financeiras para distribuir papéis produzidos por eles em todo o mundo. Isso foi um modelo de negócio que se chamou originate and distribute, originar valores, sem investir, sem trabalhar, objetivando a criação de papéis, as chamadas seguranças. Após isso, pôde-se distribuí-los e vendê-los com alto lucro em todo o mundo. Os bancos e fundos europeus compraram estas seguranças para também participar deste negócio internacional. Os papéis foram avaliados como de altíssima segurança pelas agências de classificação de risco ("rating agencies"). Estas agências são absolutamente necessárias para o funcionamento deste negócio. Então uma bolha cresceu e estourou. O resultado foi que instituições financeiras, com alto grau de importância para o funcionamento de todo o sistema, tiveram de ser salvas por pacotes de resgate financiados pelo Estado, isso é, pelo setor público. Não havia outras possibilidades já que nenhum ente privado iria salvá-las. Mas o Estado foi obrigado a fazer isso devido a alta relevância sistêmica destas instituições, o que resultou no endividamento do Estado. A mesma coisa aconteceu no Brasil nos anos 80. No início da crise (da dívida) externa brasileira, em 1982, 80\% da dívida estava ligada ao setor privado. Três anos depois, $80 \%$ da dívida externa do Brasil era pública. Foi um processo de socialização das dívidas para salvar um patrimonio privado. Isso aconteceu também na Europa, a socialização das dívidas para garantir o serviço das dívidas para os grandes patrimônios financeiros, não somente na Europa, mas também nos EUA, na China, etc. Essa é a causa do endividamento dos Estados na Europa, mesmo que haja um endividamento desigual no continente. Os países mais endividados são os países mediterrâneos.

A transferência do serviço da dívida privada para o setor público é a maneira que se organiza este processo. Porém, existem alternativas a este processo, por exemplo, o cancelamento da dívida, que é uma discussão que nós conhecemos do endividamento externo, nos anos 80. O cancelamento da dívida aconteceu nos tempos bíblicos, na Grécia antiga, mas também nos tempos modernos no caso da Alemanha em 1953: uma grande parte da dívída foi cancelada. Obviamente, os credores não querem o cancelamento porque eles encaram a dívida como um 
investimento que gera lucro. Alguns defendem ainda outras possibilidades, como o crescimento [econômico]. Mas isso não funciona, e é extremamente problemático para o desenvolvimento por causa do consumo de recursos naturais, tendo em vista a questão climática. Não é uma boa solução para o problema do endividamento o crescimento econômico. Não haverá êxito. Por isso, a única saída, do ponto de vista das instituições financeiras, é a austeridade. O Estado Nacional tenta organizar essa austeridade, porém ele é muito fraco para tal tarefa. Nessa crise do endividamento externo, os Estados Nacionais buscam suporte na Troika. Dessa forma, os governos nacionais não são mais responsáveis pelo serviço da dívida. Como resultado disso, surgem pressões externas que matam a democracia, porque não é possível decidir democraticamente quando não há soberania orçamentária. Essa não é apenas uma crise econômica e financeira. É uma crise política e social.

Intratextos: Você defende a tese de que existem importantes contradições sociais pra além da relação entre capital versus trabalho. E no artigo "Existe um marxismo ecológico?", você destacou que o conceito marxista da relação homem-natureza é mais apropriado para compreender as contradições e a dinâmica da relação social entre o ser humano e a natureza, e que não é a pobreza que produz destruição ecológica, senão as desigualdades e as injustiças que contribuiriam para a devastação ambiental. Quais são essas contradições e em quais experiências você se baseia para formular tal pensamento?

Elmar Altvater: Depende de como se analisa a relação entre capital e trabalho. Em termos de salário, lucro, isso é muito simples. A relação do homem com a natureza, no capitalismo, é uma relação entre capital e trabalho, mas as determinações dessa relação são múltiplas, encontram expressão nos movimentos ambientais. A coexistência da pobreza com a riqueza produz destruição. Os ricos consomem mais recursos que os pobres, essa é uma das expressões da riqueza, mais terra, mais recursos consumidos, alta mobilidade, grandes espaços para viver, etc. Os pobres têm de sobreviver, e às vezes as condições de sobrevivência significam a apropriação de bens públicos e de bens naturais. Em determinadas situações a pobreza também pode ser destrutiva, não só a riqueza. A riqueza, por sua vez, causa destruição, consome grandes recursos, inclusive através do desperdício. Entretanto, a meu ver, é a desigualdade no acesso aos recursos a causa central da devastação ecológica. 


\section{Intratextos: Como a teoria marxista pode contribuir para a crítica ambientalista? Como você utiliza a teoria marxista para compreender a discussão sobre a ecologia?}

Elmar Altvater: Acho que a teoria marxista é muito adequada para analisar a relação entre homem e natureza. Marx foi o único grande teórico ha historia da economia política que explicou o caráter duplo de todos os processos econômicos. Duplo no sentido de que são processos de transformação da energia, da matéria e da natureza, em valores de uso. Ao mesmo tempo é um processo de produção de valor de troca. Esse caráter duplo é muito importante porque nos torna capazes de compreender a interdependência entre as crises econômicas, financeiras, e as crises ecológicas e ambientais.

\section{Intratextos: O que é o "fetiche do crescimento" e quais são os "dilemas do crescimento"?}

Elmar Altvater: Fetiche é uma coisa produzida pelos homens, e que passa a ter domínio sobre eles mesmos. O produto domina o produtor, isso é o fetiche. Isso acontece também no crescimento. O crescimento é uma das consequências do capitalismo fóssil. Antes, na história humana, o crescimento foi muito baixo. Sempre cito uma obra de Angus Maddison, publicada pela OCDE (Organização de Cooperação e de Desenvolvimento Econômico), que se chama "A economia mundial: uma perspectiva milenar". Este estudo é sobre o crescimento nos últimos dois mil anos e mostra que o crescimento sempre esteve num nível muito baixo, até a Revolução Industrial. Só depois, no século XIX, começou a época do crescimento.

As pessoas esquecem que a normalidade na história humana foi o não-crescimento. E hoje, o crescimento aparece como algo natural. Por isso existe no Brasil o Programa de Aceleração do Crescimento (PAC). Na Alemanha, nós temos uma lei de aceleração do crescimento. A isso chamo, junto com outros teóricos, não é minha criação, de "fetiche do crescimento", porque o crescimento é produzido pelo homem, não é uma coisa natural. Hoje se vê o crescimento como solução para todos os problemas econômicos e ecológicos. Por isso a palavra crescimento verde. Um crescimento verde como solução para a crise ecológica, e não só para a crise econômica e financeira. Isso é fetichismo.

INTRATEXTOS, Rio de Janeiro, 4(1): 312-326, 2012.

Página 322 
Intratextos: Na América Latina, vivemos um momento de muitas mudanças; Na última década, com a ascensão de governos de centro-esquerda, muitos autores vem debatendo o que seria um período "pós-neoliberal”, a exemplo das experiências boliviana, venezuelana equatoriana. Ao mesmo tempo, também está em debate o modelo de desenvolvimento na região, marcado por um possível processo de desindustrialização e reprimarização da economia. Como você enxerga o atual processo de desenvolvimento capitalista latinoamericano? E o brasileiro?

Elmar Altvater: Na América Latina, o problema é bem claro. Em primeiro lugar, há uma mudança na direção do pós-neoliberalismo, isso é claro, porque o neoliberalismo entra em crise em todo o mundo. O segundo ponto é de que, no novo século, a situação global mudou. Não se pode dizer isso com plena certeza, mas talvez os preços das matérias-primas sobem por causa dos limites dos recursos. Também existem outros aspectos, como o surgimento de novos consumidores nos países emergentes, na China, na Índia e no Brasil. São consumidores novos, o que faz com que o preço desses recursos cresça. Não somente o preço dos recursos naturais, mas também dos alimentos. Dessa maneira, aumenta-se a demanda por energias fósseis. Por isso, na América Latina, torna-se muito rentável produzir e negociar matérias-primas. Daí vem o neoextrativismo nos países latino-americanos, que é uma possibilidade de melhorar os Estados de Bem-Estar. O socialismo do século XX foi caracterizado, pelo historiador e sociólogo britânico Raymond Williams, como o "socialismo da redistribuição", e isso acontece agora na América Latina. Antigamente, a riqueza das nações, aqui na América Latina, foi transferida para as grandes empresas transnacionais. Hoje em dia, com a força dos governos populares de esquerda, em muitos países latino-americanos, é possível apropriar-se dessa riqueza através do Estado, redistribuindo essa riqueza para os pobres e para os atingidos pela crise, etc. Isso é possível. Os governos fazem isso através de programas sociais, como o Bolsa-Família aqui no Brasil, na Venezuela, Bolívia, Equador, Colômbia e em outros países. Não é o socialismo como um outro modo de produção, é apenas uma forma de redistribuição. Não é uma mudança, uma revolução, no que diz respeito ao poder, sua transformação em poder popular. Isso não aconteceu na Europa, sob o socialismo da redistribuição, e não acontece na América Latina, sob a mesma lógica de socialismo de redistribuição. 


\section{Intratextos: Como você avalia a experiência da construção do socialismo no século XX? Quais foram os principais erros e acertos?}

Elmar Altvater: Nós temos que refletir sobre o "socialismo realmente existente", sobre sua experiência, e não foi uma boa experiência. Isso por causa de, pelo menos, dois aspectos. $\mathrm{O}$ primeiro é o seu fracasso histórico, porque alguns princípios não têm condições de ser repetidos ou de ter influência neste novo século, por exemplo: o partido único, o culto aos dirigentes, a falta de participação democrática, no sentido formal, a falta de espaços mais livres. Na economia também houve vários problemas: o primeiro e, talvez, o maior, é o planejamento central. Como ecologistas do século XXI, nós sabemos da diversidade de espécies, da multiplicidade da evolução, como uma das pré-condições para a sobrevivência e futuro da humanidade. Estes são princípios que não permitem um planejamento centralizado. O planejamento deve ser organizado democraticamente, cooperativamente. Existem também os espaços que devem ser regulados pelo mecanismo do mercado.

Apesar disso, o combate ao problema das mudanças climáticas deve ser planejado num nível central, talvez global. Isso significa uma pluralidade de escalas e de decisões econômicas e sociais. O princípio do planejamento central e nacional, que vigorou no século $\mathrm{XX}$, não pode funcionar em outros âmbitos.

A maneira como se deu o planejamento nacional dos países socialistas, em sua integração ao mercado mundial, sobretudo no mercado financeiro, significou endividamento externo em moeda forte, em dólares. E para receber investimentos os países deveriam ser competitivos no sentido dos países ocidentais. Isso significou o fim do "socialismo realmente existente", porque é uma repetição do modelo ocidental, e não vai na direção do socialismo. Essa foi, provavelmente, a razão pela qual fracassou o "socialismo real". A queda do muro de Berlim, em 1989, foi muito pacífica, não houve resistência naqueles países uma vez que as sociedades já eram capitalistas. Apenas eram chamados de "socialistas", e por isso elas, muito rapidamente, reproduziram o modelo capitalista.

Intratextos: Quais as possibilidades de alternativas ao capitalismo? 
Elmar Altvater: Atualmente existem alguns conceitos no debate sobre as alternativas: o socialismo do século XXI do Chávez; os debates sobre a economia solidária em todos os países latino-americanos e na Europa; os velhos conceitos de cooperativas, que se renovam. Este ano de 2012, é o ano das cooperativas nas Nações Unidas. Existem várias tentativas neste sentido, às vezes essas alternativas são temporárias. Na Argentina, após a crise de 2001, surgiram muitas cooperativas nas ocupações de fábricas. Eles se reorganizaram, nas fábricas recuperadas, em modos alternativos em comparação à situação anterior. O Estado legalizou essas cooperativas. No entanto, quando se observa, dez anos depois, quais foram as conseqüências, não se encontra muita coisa alternativa, porque sempre há um movimento pendular: primeiro alternativas e depois volta-se à normalidade. As alternativas surgem como remédios para combater uma crise aguda. Quando a crise acaba, a normalidade volta. Esta foi também uma experiência pós II Guerra Mundial. Haviam muitas alternativas na Europa. Entretanto veio o milagre econômico na Alemanha, Itália, e em outros países, com altas taxas de crescimento, e assim voltaram ao capitalismo. Alternativas precisam criar raízes profundas. Como na natureza, assim como na história social.

Há também na Bolívia o conceito de buen vivir, mãe terra, que é uma das tentativas de estabelecer uma alternativa ao capitalismo. Na Bolívia, como em outros países da esquerda latino-americana, existem estratégias econômicas neo-extrativistas. Isso é uma contradição destes governos: um lado segue a linha do buen vivir, da mãe terra, uma linha ecológica, social, e humana, e, do outro lado, a extração das riquezas para a valorização no mercado mundial. Isso é uma contradição que não tem reconciliação.

Estas são as perguntas mais importantes. Temos que discutir sobre estes pontos sempre. Nas próximas semanas, como nos próximos anos.

Intratextos: Professor, estamos chegando ao fim da entrevista, há algo mais que você queira dizer, dentro de tudo que debatemos aqui? Deixar alguma mensagem para os alunos...

Elmar Altvater: As discussões que tive nos seminários da UERJ foram muito boas. Não se pode pensar que temos respostas para todas estas perguntas, mas é necessário, e faz muito sentido, discutir estas questões seriamente, e, depois da discussão, agir.

INTRATEXTOS, Rio de Janeiro, 4(1): 312-326, 2012.

Página 325 
Nós discutimos, no início desta entrevista, como os intelectuais estão envoltos na academia, nas universidades, com suas regras, que nós temos estabelecido e que, portanto, são passíveis de mudança. Ainda que também devamos respeitar as regras do sistema científico, da pesquisa. Por outro lado, somos militantes dos movimentos e temos de mudar a situação social, analisar passo a passo as alternativas, discuti-las, enfim, desenvolver essas alternativas. Essa é uma necessidade.

O socialista italiano, que foi senador na República italiana nos anos 60 e 70, Lelio Basso, fundador do tribunal dos direitos dos povos, tem uma boa palavra: ricerca collectiva, pesquisa coletiva. Pesquisa coletiva não no sentido em que muitas pessoas fazem as pesquisas, mas ricerca collectiva como um movimento do pesquisador à realização do pesquisado através da prática política na qual, também, o pesquisador participa. Um círculo coletivo, a ricerca collectiva, pesquisa coletiva. Acho que essa é uma boa indicação do que os pesquisadores críticos têm a fazer nas universidades. Quando falamos da responsabilidade do pesquisador, também é parte da responsabilidade discutir com vocês (risos). 